\title{
Inheritance Pattern of Earliness and Yield Related-Traits in Spring Barley (Hordeum vulgare L.)
}

\author{
A. Elakhdar ${ }^{1,2}$, T. Kumamaru ${ }^{1}$, M. Abd El-Aty ${ }^{3}$, Kh. Amer ${ }^{2}$, I. Eldegwy ${ }^{3}$, I. Elakhdar ${ }^{4} \&$ M. Noaman ${ }^{2}$ \\ ${ }^{1}$ Faculty of Agriculture, Kyushu University, Fukuoka, Japan \\ ${ }^{2}$ Field Crop Research Institute, Agricultural Research Center, Giza, Egypt \\ ${ }^{3}$ Crop Science Department, Faculty of Agriculture, Kafrelsheikh University, Egypt \\ ${ }^{4}$ Soil, Water and Environment Research Institute, Agricultural Research Center, Giza, Egypt \\ Correspondence: A. Elakhdar, Faculty of Agriculture, Kyushu University, Hakozaki 6-10-1, Fukuoka 812-8581, \\ Japan. Tel: 81-92-642-3057. E-mail: a.elakhdar@kyudai.jp
}

\author{
Received: February 7, $2017 \quad$ Accepted: March 17, $2017 \quad$ Online Published: May 15, 2017 \\ doi:10.5539/jas.v9n6p142 URL: https://doi.org/10.5539/jas.v9n6p142
}

\begin{abstract}
To understand the genetic patterns of the physio-morphological traits for barley grain yield, six-generations $\left(\mathrm{P}_{1}\right.$, $\mathrm{P}_{2}, \mathrm{~F}_{1}, \mathrm{~F}_{2}, \mathrm{BC}_{1}$, and $\mathrm{BC}_{2}$ ) were used to determine the type of gene action in the four barley crosses. Grain yield showed a strong positive association $(r=0.83$ and 1$)$ with Grain Filling Rate in Giza121/RIL1 and Giza126/RIL2 crosses, respectively. The relationship between yield and earliness was not consistent with crosses and positive (r) values were quite low. It should be possible to select early-maturing and high-yielding segregates with high 100- kernel weight. The results indicated that the dominance effect [dd] was more important and greater than the additive effect [aa] and [ad] for most traits. Positive heterosis over the mid- and better- parent was quite similar for the most traits, except for heading and maturity dates, that showed negative heterotic effects. The inbreeding depression was high significant and positive for Grain Filling Rate, chlorophyll contents, Flag Leaf area and 100- kernel weight. On the other hand, it was a negatively significant for the earliness trait (HD, MD, and GFP). The lack of uniformity for estimates of inbreeding depression can be explained by environmental variation and to its influence on the type of gene action. Narrow-sense heritability ranged from $13.3 \%$ for Grain Filling Period in Giza12/RIL1 to $66.6 \%$ for heading dates in Giza121/RIL2 crosses. Genetic advance estimates were low due to lack of additive variance. The crosses Giza121/RIL1 and Giza126/RIL2 would be of interest in a breeding program, for improving characteristics of earliness, yield, and its components.
\end{abstract}

Keywords: Hordeum vulgare L., type of gene action, heterosis, heritability

\section{Introduction}

Barley (Hordeum vulgare L.) is a crop with great adaptive potential in many regions of the world. In areas which have only a brief rainy season, growers can obtain a harvest mainly because this crop has advantages in aspects such as salt tolerance, frost tolerance in the early period of development, drought tolerance, etc. Breeding for quantitative traits in early generations is impeded by several factors such as polygenic nature and low heritability of a trait (grain yield, the number of spikes per plant, etc.), linkage, non-additive gene effects and environmental effects (Harlan, 1976).

In order to overcome these difficulties, it is necessary to get as much information as possible about the genetic structure of breeding population undergoing selection (Sharma et al., 2003). This means identifying the gene effects that control the inheritance of a trait of interest and contributing to the exploitable genetic variance of the population.

Grain yield increase would be effectively rested with the basis of the capabilities of yield components and other closely associated traits. In cereal crops, the upper three leaves on the stem, especially the uppermost leaf, i.e., flag leaf, are the primary source of carbohydrate production. The flag leaf could contribute a large proportion of the carbohydrates stored in grains. The morphological traits of flag leaf such as size and shape and its physiological traits such as chlorophyll content and photosynthesis capacity have been considered to be the important determinants of grain yield in cereals (Abd El-Aty et al., 2011). 
According to (Falconer \& Mackay, 1996) heritability is defined as the measure of the correspondence between breeding values and phenotypic values. Thus, heritability plays a predictive role in breeding, expressing the reliability of phenotype as a guide to its breeding value (Addisu et al., 2015). There is a direct relationship between heritability and response to the selection, which is referred to as genetic advance. High genetic advance with high heritability estimates offers the most effective condition for selection (Yadav et al., 2015). The value of heritability, therefore, increases when it is used to calculate genetic advance, which indicates the degree of gain in a characteristic obtained under a particular selection pressure. Thus, genetic advance is another important selection parameter that helps breeder in a selection program. Moreover, most agronomical important traits, including grain yield, have complex genetic inheritance and require the use of relatively large populations for studying plant breeding. In self-pollinating, segregating populations, the frequency of individuals with all favorable alleles is reduced with generation advance (Addisu \& Shumet, 2015).

The present study is seeking to estimate the type of gene action, heterosis, heritability, and genetic advance on the base of individual segregating populations for grain yield, earliness and some physiological characteristic in spring barley.

\section{Materials and Methods}

\subsection{Experimental Site}

The field experiment was conducted at the Experimental Farm of Sakha Agricultural Research Station $31.3^{\circ} \mathrm{N}$, $30.9^{\circ} \mathrm{E}$, Agricultural Research Center (ARC), Egypt during three winter seasons. The experimental soil was clayey, $\mathrm{pH} 8.2$ and organic matter content in the soil was about $1.4 \%$. The average annual rainfall of the region was $180 \mathrm{~mm}$ during the growing season.

\subsection{Germplasm}

Four six-row spring barley genotypes were used in this investigation; Giza121 and Giza126 are Egyptian cultivars with good agronomic characteristics; maturity 136 and 144 days, respectively; susceptible to powdery mildew and leaf rust. The RIL1 and RIL2 lines were introduced from The International Center for Agricultural Research in the Dry Areas (ICARDA) and exhibit height, stiff straw strength, early maturity, resistant to stem rust and moderately to powdery mildew (Table 1 ). The differences among the parents had been determined using Sodium Dodecyl Sulfate-Polyacrylamide Gel Electrophoresis (SDS-PAGE) (Laemmli, 1970).

Table 1. Production of backcross progenies from the four crosses.

\begin{tabular}{lll}
\hline Crosses & \multicolumn{2}{c}{ Backcrosses } \\
\hline $\mathrm{F}_{1}$ & $\mathrm{BC}_{1}$ & $\mathrm{BC}_{2}$ \\
\hline Giza121/RIL1 & Giza121/RIL1/Giza121 & Giza121/RIL1/RIL1 \\
Giza121/RIL2 & Giza121/RIL2/Giza121 & Giza121/RIL2/RIL2 \\
Giza126/RIL1 & Giza126/RIL1/Giza126 & Giza126/RIL1/RIL1 \\
Giza126/RIL2 & Giza126/RIL2/Giza126 & Giza126/RIL2/RIL2 \\
\hline
\end{tabular}

\subsection{Procedure}

Parents were planted in the first seasons 2008/09 and the following crosses were made: Giza121/RIL1, Giza121/RIL2, Giza126/RIL1, and Giza126/RIL2.

In 2009/10 season; seeds of the, $F_{1}$ 's were sown to produce, $F_{1}$ plants. Each of $F_{1}$ plants was crossed back to their respective parent to produce first correspondent backcross $B C_{1}$ and $B C_{2}$. In the meantime, the four parents were re-crossed to produce the $F_{1}$ 's seeds. However, $F_{1}$ Plants not used in backcrosses were self-pollinated to produce $F_{2}$ seed (Figure 1). 


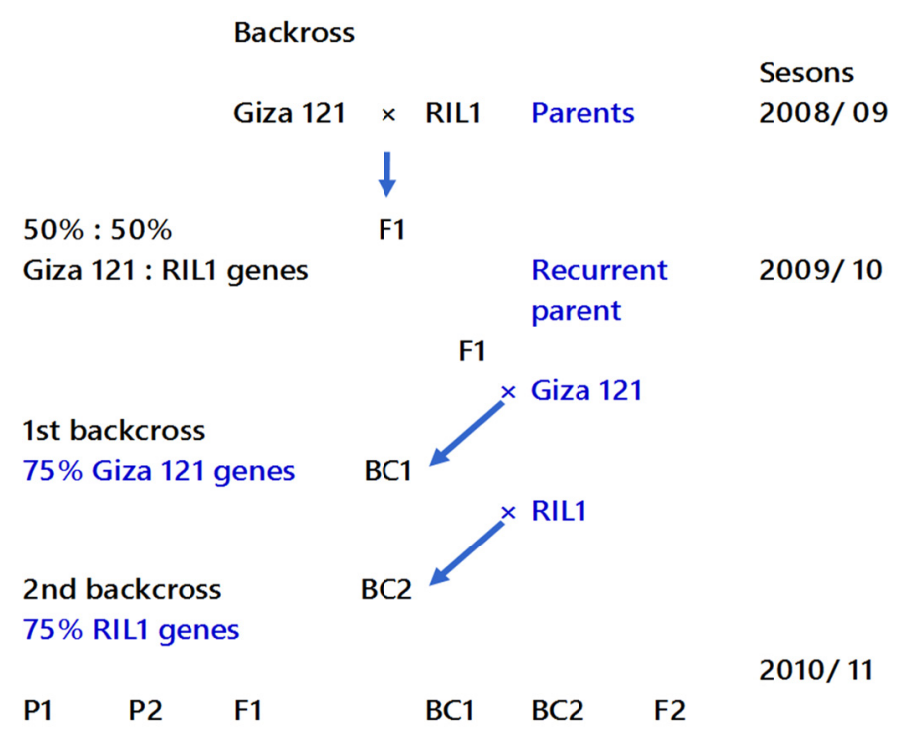

Figure 1. Apply the general principles of managing segregating populations generated from parental crossing

In 2010/11 season, the obtained seeds of the six populations $P_{1}, P_{2}, F_{1}, F_{2}, B C_{1}$ and $B C_{2}$ of the four crosses were grown together in a randomized complete block design RCBD with three replications by hand in each $3 \mathrm{~m}$ row to ensure accuracy of within row spacing of $10 \mathrm{~cm}$, the rows were spaced $30 \mathrm{~cm}$ apart. Each replication composed of 17 rows as follows, and the generations were distributed randomly within the replications (Table 2).

Table 2. The individual of the six-population plants from four crosses

\begin{tabular}{lll}
\hline Population & No Rows & No individual Plants \\
\hline$P_{1}$ & 1 & 30 \\
$P_{2}$ & 1 & 30 \\
$F_{1}\left(P_{1} \times P_{2}\right)$ & 1 & 30 \\
$F_{2}$ & 10 & 300 \\
$B C_{1}\left(\right.$ Backcross of $P_{1}$ to $\left.F_{1}\right)$ & 2 & 75 \\
$B C_{2}\left(\right.$ Backcross of $P_{2}$ to $\left.F_{1}\right)$ & 2 & 75 \\
Total & & $540 \times 4$ crosses $=2160$ \\
\hline
\end{tabular}

\subsection{Recording Data}

Data were collected on 2160 individual plants based on the following characteristic: (1) Earliness: Heading date HD, Maturity date MD, Grain Filling Period GFP. (2) Growth stage characteristic: Flag leaf area FL $\left(\mathrm{cm}^{2}\right)$, Total chlorophyll content/ plant Ch SPAD value. (3) Yield components characteristic: Grain Filling Rate GFR (g/day/plant), 100- kernel weight KW, Grain yield/plant GY.

\subsection{Biometrical Analysis}

The population means and the variances; were used to carry on the Scaling test as outlined by Hayman and Mather (1955) to determine the presence of non-allelic gene interactions.

The population means and variance were used to estimate the type of gene action. One tail $\mathrm{F}$ ratio was used to test the significance of $F_{2}$ variance as follows: $\mathrm{F}=\mathrm{VF} 2 / \mathrm{VE}$, where, $\mathrm{VE}=$ [VP1 $\left.+\mathrm{VP} 2+\mathrm{VF} 1\right] / 3$ (Allard \& Jain, 1962). The "t" test was used to test the significance difference between the two parents in each cross.

\subsection{Scaling Test}

It gave four tests for scale effects A, B, C and D. The significance of any one of these scales is taken to indicate the presence of non-allelic interactions. In each test, the degree of freedom is the sum of the degrees of freedom of various generations involved (Hayman \& Mather, 1955). 
Types of gene action; additive (A) and dominance (D) variance were estimated by (Gamble, 1962) partitioning method of the components of variance employing parents, $\mathrm{F}_{1}$ 's, $\mathrm{F}_{2}$ 's and reciprocal backcrosses. Phenotypic variance components of the $F_{2}$ generation are: $\mathrm{VF} 2=1 / 2 \mathrm{~A}+1 / 4 \mathrm{D}+\mathrm{E}$, and $(\mathrm{VBC} 1+\mathrm{VBC} 2)=1 / 2 \mathrm{~A}+1 / 2 \mathrm{D}+\mathrm{E}$.

The standard error of [a], [d], [aa], [ad] and [dd] was obtained by taking the square root of their respective variances. " $t$ " test values were calculated by dividing the effects of a, $d$, aa, ad and dd on their respective standard errors.

\subsection{Heterosis}

Heterosis was expressed as the percentage of the deviation of $F_{1}$ hybrid over mid $H_{M P}$ and better parent $H_{B P}$ values. $H_{M P}=\left(\overline{\mathrm{F}_{1}}-\overline{\mathrm{MP}}\right) / \overline{\mathrm{MP}} \times 100 ; H_{B P}=\left(\overline{\mathrm{F}_{1}}-\overline{\mathrm{BP}}\right) / \overline{\mathrm{BP}} \times 100$.

Inbreeding depression $I D \%$ was calculated as the difference between the $F_{1}$ and $F_{2}$ means expressed as a percentage of the $F_{1}$ mean. $I D \%=\left(\overline{\mathrm{F}_{1}}-\overline{\mathrm{F}_{2}}\right) / \overline{\mathrm{F}_{1}} \times 100$, Variances of ID deviation $=\overline{\mathrm{VF}_{1}}+\overline{\mathrm{VBP}}$.

Potence ratio; (Smith, 1952) proposed the potence ratio (PR), which can be used to determine the degree of dominance. Potence ratio $=\overline{\mathrm{F}_{1}}-\overline{\mathrm{MP}} /\left[1 / 2\left(\overline{\mathrm{P}_{2}}-\overline{\mathrm{P}_{1}}\right)\right]$.

\subsection{Estimation of Heritability and Genetic Advance}

Heritability was estimated using two different methods, broad sense, $h_{b s}$ and narrow sense heritability as follows: broad sense $\mathrm{h} 2_{\mathrm{bs}}=\mathrm{VG} 2 / \mathrm{Vph} \times 100$; (Allard \& Jain, 1962), where,

$\mathrm{VG}=\mathrm{VF} 2 / \mathrm{VE}$, and $\mathrm{Vph}($ total variance $)=\mathrm{VF} 2$.

Narrow sense; $h_{n s}^{2}=(1 / 2 D) / F^{2} \times 100$ (Hayman \& Mather, 1955). Where, $V D=\overline{V_{2}}-\overline{V_{B C}}-\overline{V_{B C}}$.

The expected genetic advance under selection $(\Delta \mathrm{g})$ was estimated according to (Johnson et al., 1955) $\Delta \mathrm{g}=\mathrm{K} \times \sqrt{\mathrm{VF}_{2}} \times \mathrm{h}^{2} \times 10$, where, $\mathrm{K}$ value is a selection differential with a value of 2.06 under $5 \%$ selection. In addition, this expected gain was expressed as a percentage of $F_{2}$ mean $(\Delta \mathrm{g} \%)$ according to (Miller et al., 1958) as follows: $\Delta \mathrm{g} \%=\Delta \mathrm{g} / \mathrm{F}_{2} \times 100$.

\section{Results}

\subsection{The Mean Yield Performance}

The molecular variation between the parents was presented in SDS-PAGE. The dendrograms (Figure 2) show that the most variance between the parents was in prolamin fractions (hordeins).

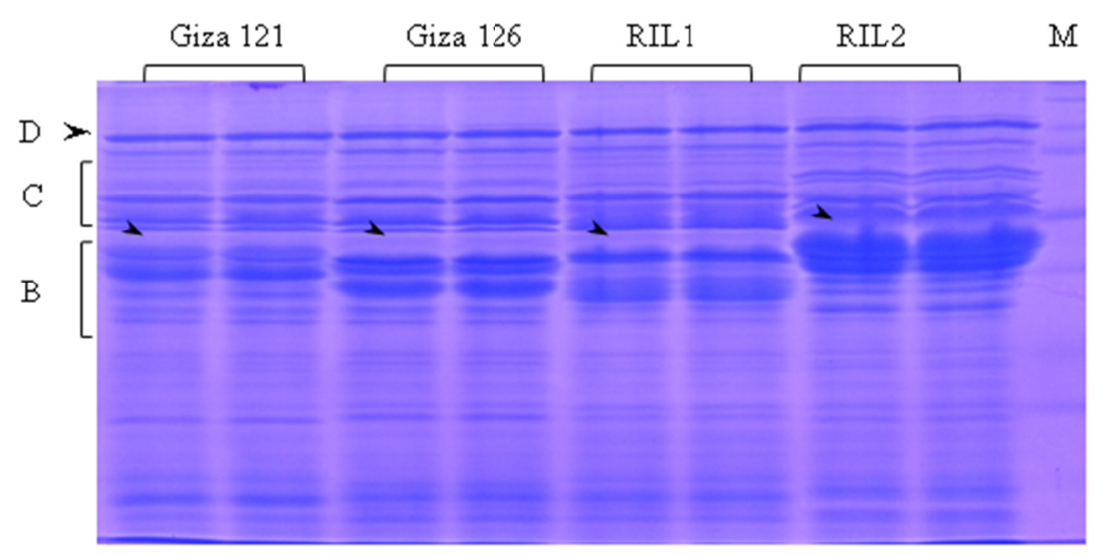

Figure 2. SDS-PAGE analysis of total protein fractions from the four parents

Note. The arrow track indicates D-hordein $>100 \mathrm{kDa}$ and the brackets indicate, in order of increasing mobility downward, C-hordeins 55-75 kDa and 35-46 kDa B-hordeins.

The mean yield performance for the six-population was significant among generations in all traits (Supplemental Table 1). The parental means for HD were different from each other. The $F_{1}$ Giza121/RIL1 mean (87.97 days) was significantly different from the later heading parent, Giza 126 (99.07 days). The $F_{2}$ means were as expected intermediate to the parental means but were closer to the late parent. The BCs, in most cases, deviated from the $F_{2}$ in the direction of the recurrent parent. The segregation of GY trait was continuously distributed in $F_{2}$ 's among all crosses (Figures 3a, 3b, 3c, and 3d), but showed significant transgressive distribution, indicating their 
normal distribution. Additionally, transgressive segregation in both directions was observed for all traits (data not shown); mean that both parents transmitted favorable alleles for each trait (Figures $4 a, 4 b, 4 c$, and 4d).
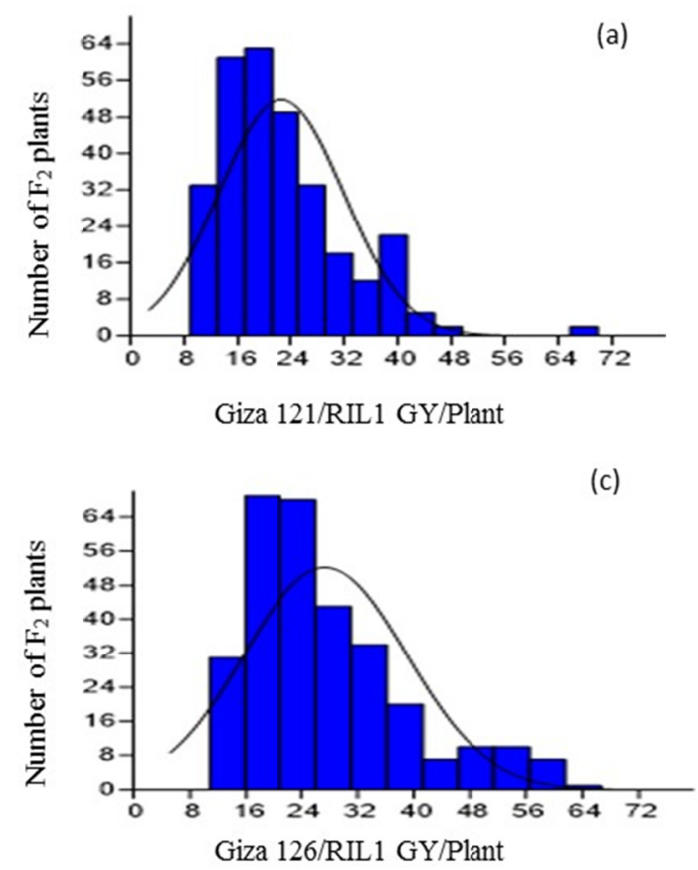

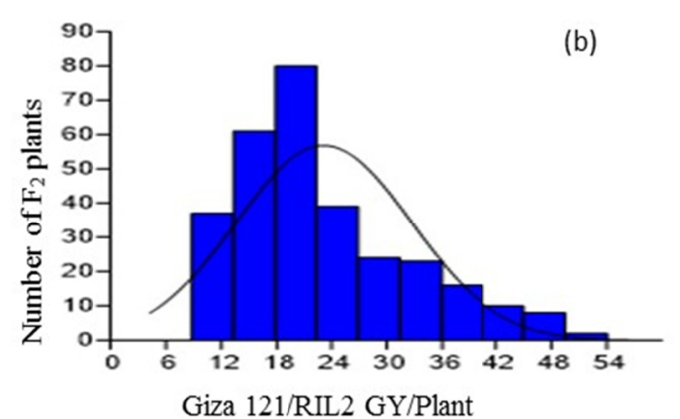

(d)

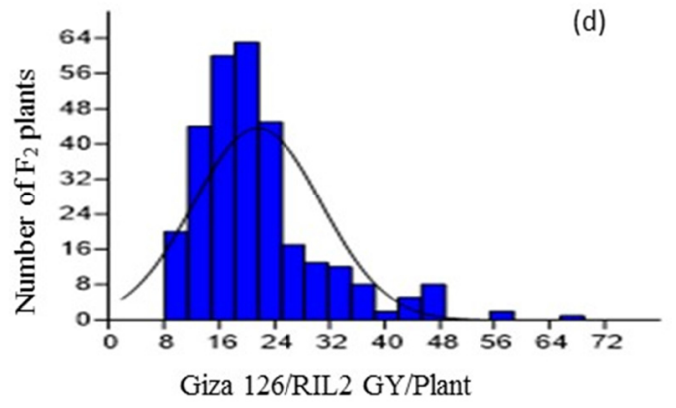

Figure 3. Histogram of pooled $F_{2}$ population for grain yield/plant in the four crosses; (a) Giza12/RIL1, (b) Giza121/RIL2, (c) Giza126/RIL1, and (d) Giza126/RIL2
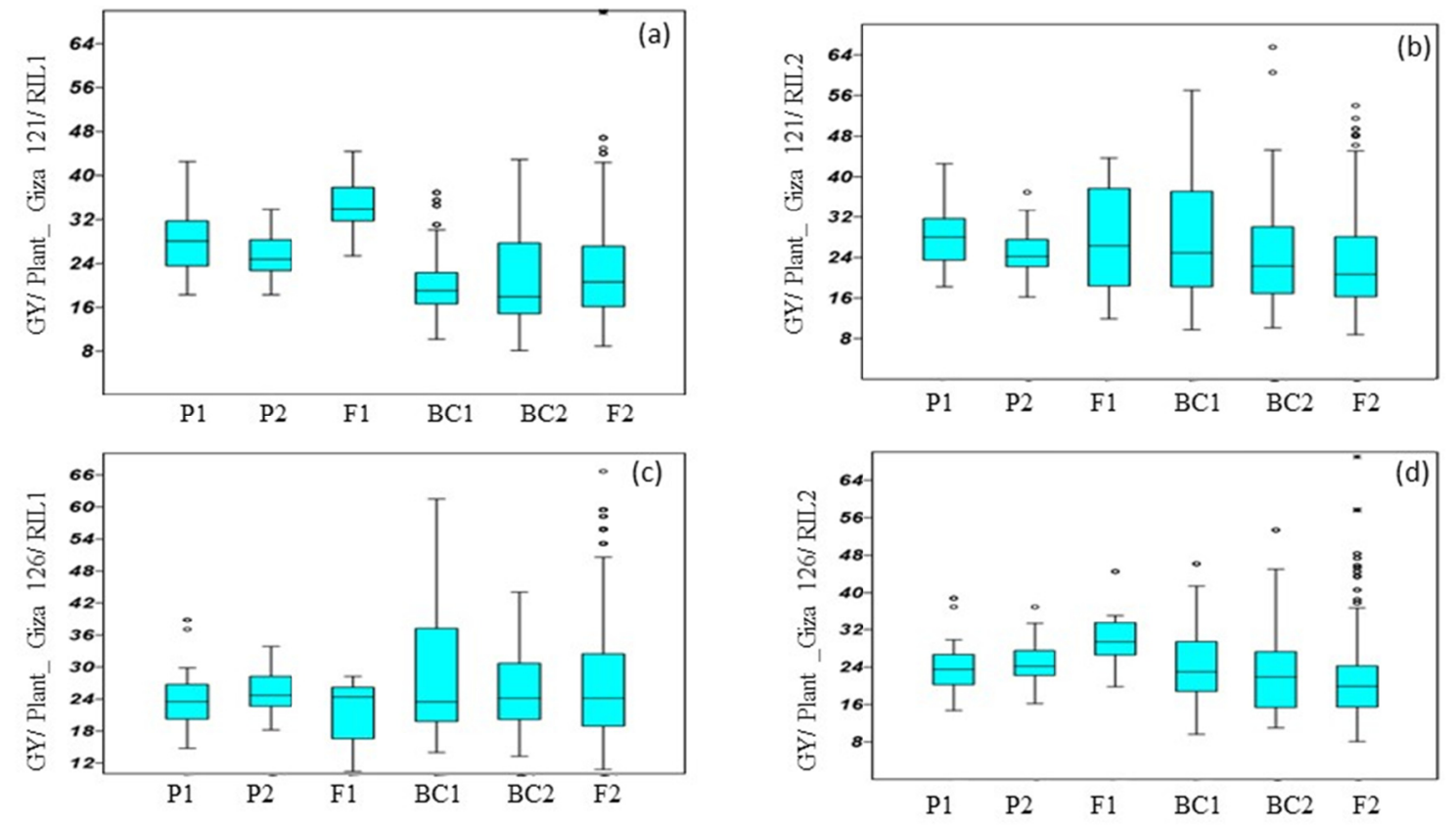

Figure 4. Box plots for performances of parents and crosses for GY/plant (g. The plus sign ' ${ }^{\circ}$ ' stands for outliers. The upper and lower lines outside the box stand for max and min adjacent value, respectively. The line inside the box stands for median value. The upper and lower hinges of the box stand for $75 \%$ and $25 \%$ percentile, respectively; (a) Giza12/RIL1, (b) Giza121/RIL2, (c) Giza126/RIL1, and (d) Giza126/RIL2 
Concerning the phenotypic correlation coefficients, the results although many rather small correlation coefficients are statistically significant, $r$ values below 0.4 have little practical significance because they indicate the relationship between the two characteristics accounts for only a GFR of the total variation. High yielding segregates with high kernel weight can probably be selected since $r$ values were almost always positive. The results of correlation analysis among the eight traits are shown in (Table 3). The FL was significantly and positively correlated $(\mathrm{P} \leq 0.01)$ with GFR and GY in $\mathrm{C} 1$; $\mathrm{HD}$ and GY in $\mathrm{C} 2$; GFR with $\mathrm{KW}$ and GY in addition, $\mathrm{KW}$ and GY in $\mathrm{C} 3$ and GFR with FL and GY, plus FL and GY in C4, indicating that FL, GFR, and KW was associated with GY/plant.

Table 3. The correlation coefficients among eight traits of the $F_{2}$ population

\begin{tabular}{|c|c|c|c|c|c|c|c|c|c|c|c|c|c|c|c|c|c|}
\hline$\overline{\mathrm{C} 1}$ & HD & MD & GFP & GFR & $\mathrm{Ch}$ & FLA & KW & GY & $\mathrm{C} 2$ & HD & MD & GFP & GFR & $\mathrm{Ch}$ & FLA & KW & GY \\
\hline HD & & & & & & & & & HD & & & & & & & & \\
\hline MD & -0.06 & & & & & & & & MD & $0.12^{*}$ & & & & & & & \\
\hline GFP & 0.07 & $-0.17^{*}$ & & & & & & & GFP & $-0.13^{*}$ & $-0.19^{*}$ & & & & & & \\
\hline GFR & 0.03 & 0.01 & -0.07 & & & & & & GFR & $0.17^{*}$ & 0.08 & -0.01 & & & & & \\
\hline $\mathrm{Ch}$ & $-0.15^{*}$ & 0.05 & -0.02 & 0.02 & & & & & $\mathrm{Ch}$ & -0.01 & 0.01 & 0.00 & -0.04 & & & & \\
\hline FL & -0.11 & -0.05 & $0.24 * *$ & $-0.12 *$ & -0.03 & & & & FL & $0.11^{*}$ & -0.03 & 0.02 & 0.07 & -0.03 & & & \\
\hline KW & -0.02 & 0.03 & -0.08 & 0.01 & 0.01 & -0.04 & & & KW & 0.04 & -0.02 & 0.00 & -0.02 & -0.03 & -0.07 & & \\
\hline GY & 0.03 & 0.06 & -0.05 & $0.83 * *$ & 0.01 & -0.09 & -0.02 & & GY & $0.16^{*}$ & 0.07 & 0.04 & 1.00 & -0.03 & 0.07 & -0.02 & \\
\hline $\mathrm{C} 3$ & HD & MD & GFP & GFR & $\mathrm{Ch}$ & FLA & KW & GY & $\mathrm{C} 4$ & HD & MD & GFP & GFR & $\mathrm{Ch}$ & FLA & KW & GY \\
\hline HD & & & & & & & & & HD & & & & & & & & \\
\hline MD & $-0.14 *$ & & & & & & & & MD & -0.02 & & & & & & & \\
\hline GFP & -0.06 & -0.04 & & & & & & & GFP & $-0.20 *$ & -0.03 & & & & & & \\
\hline GFR & 0.01 & 0.04 & $-0.12 *$ & & & & & & GFR & 0.01 & 0.00 & -0.05 & & & & & \\
\hline $\mathrm{Ch}$ & 0.05 & 0.09 & $-0.12 *$ & 0.07 & & & & & $\mathrm{Ch}$ & -0.06 & 0.06 & $-0.13 *$ & 0.05 & & & & \\
\hline FL & -0.04 & 0.00 & -0.02 & -0.01 & 0.02 & & & & FL & 0.00 & 0.01 & 0.03 & $0.10^{*}$ & 0.03 & & & \\
\hline KW & 0.09 & 0.02 & $-0.11^{*}$ & $0.13^{*}$ & 0.03 & $-0.11^{*}$ & & & KW & -0.03 & -0.02 & $-0.16^{*}$ & 0.01 & 0.03 & -0.08 & & \\
\hline GY & -0.07 & 0.00 & 0.02 & $0.79 * *$ & 0.03 & -0.01 & $0.11^{*}$ & & GY & 0.00 & 0.00 & 0.01 & $1.00 * *$ & 0.04 & $0.10^{*}$ & 0.00 & \\
\hline
\end{tabular}

Note. HD: heading date; MD: maturity date; GFP: Grain filling period; GFR: grain filling rate; Ch: Chlorophyll content; FL: flag leaf area; KW: 100-karnels weight (g); GY; grain yield (g/plant). C1: Giza121/RIL1; C2: Giza121/RIL2; Giza126/RIL1; Giza126/RIL2. * and **: significant and highly significant at $95 \%$ and $99 \%$ probability levels, respectively.

\subsection{Mode of Gene Action}

The results of the six-parameter model and type of epistasis revealed the presence of a non-allelic interaction for most studied characteristics in the most studied crosses except for $\mathrm{C} 4$ cross in $\mathrm{Ch}$ and GY that indicated the absence of a non-allelic interaction (Table 4). It is worthy to mention that at least one of the A, B and C tests was significant for the previous characteristics, indicating adequacy of the six-parameter model to explain the type of gene action controlling the traits in these crosses. Additive gene effects [a] were quite small in magnitude relative to the dominance gene effects. Significant or highly significant positive additive gene effects [a] were obtained for $\mathrm{HD}$ in the $\mathrm{C} 3$ and $\mathrm{C} 4$ crosses, $\mathrm{MD}$ in the $\mathrm{C} 1, \mathrm{C} 3$ and $\mathrm{C} 4$ crosses, and all crosses for FL. On the other hand, it was negative significant for HD and MD in $\mathrm{C} 2$; GFP in C1; GFR in $\mathrm{C} 3$ and $\mathrm{C} 4$; $\mathrm{Ch}$ in all crosses except for $\mathrm{C} 1$. The major contribution by dominance [d] effects to variation in $\mathrm{C} 2, \mathrm{C} 3$ and $\mathrm{C} 4$ crosses in all traits except for GFR and FL.

\subsection{Heterosis, Inbreeding Depression and Potence Ratio of the $F_{1}$ Hybrids}

Estimates of heterosis are specific to each particular cross and are affected by the environment (supplemental Table 2). The genes by which two lines differ will not be the same for all pairs of lines, so different pairs of lines will have different values and will show different amounts of heterosis. The heterosis of MD\% was quite similar among crosses to HD, but there was essentially no heterosis over the high parent. Positive highly significant heterosis over mid- parent in most crosses was detected in most studied traits except for HD, MD, and GFP (Figure 5a, 5b, 5c, and 5d). 
Table 4. Scaling tests and gene effects estimates for all studied traits in the four crosses

\begin{tabular}{|c|c|c|c|c|c|c|c|c|c|}
\hline HD & $\mathrm{C} 1$ & $\mathrm{C} 2$ & $\mathrm{C} 3$ & $\mathrm{C} 4$ & $\mathrm{MD}$ & $\mathrm{C} 1$ & $\mathrm{C} 2$ & $\mathrm{C} 3$ & $\mathrm{C} 4$ \\
\hline$\overline{[\mathrm{m}]}$ & $92.86^{* *}$ & $95.27 * *$ & $97.84 * *$ & $98.60 * *$ & {$[\mathrm{~m}]$} & $137.86^{* *}$ & $139.60 * *$ & $138.86^{* *}$ & $140.48 * *$ \\
\hline [a] & 0.77 & $-6.07 * *$ & $7.42 * *$ & $1.41^{*}$ & {$[\mathrm{a}]$} & $2.610 * *$ & $-1.900 * *$ & $2.357 * *$ & $2.783^{* *}$ \\
\hline [d] & $-8.53 * *$ & $4.91 * *$ & $-10.26^{* *}$ & 0.31 & [d] & -2.67 & $-11.70 * *$ & $6.97 * *$ & 0.46 \\
\hline [aa] & $-8.30 * *$ & $6.25^{* *}$ & $-7.45 * *$ & 2.17 & [aa] & -1.62 & $-10.60 * *$ & $7.10 * *$ & 2.33 \\
\hline [ad] & -0.5 & $-2.98 * *$ & $3.86^{* *}$ & 1.21 & [ad] & $2.03 * *$ & 1.2 & $-2.24 * *$ & -0.62 \\
\hline [dd] & 1.63 & $-19.81 * *$ & $-6.77 * *$ & $-6.99 *$ & [dd] & -5.03 & $17.40 * *$ & $-9.09 * *$ & $-6.31^{*}$ \\
\hline Epistasis & Dupl. & Dupl. & Comp. & Dupl. & Epistasis & Comp. & Dupl. & Dupl. & Dupl. \\
\hline \multicolumn{5}{|l|}{ GFP } & \multicolumn{5}{|l|}{ GFR } \\
\hline$[\mathrm{m}]$ & $45.00 * *$ & $45.57 * *$ & $47.13 * *$ & $45.27 * *$ & {$[\mathrm{~m}]$} & $0.60 * *$ & $0.52 * *$ & $0.52 * *$ & $0.51 * *$ \\
\hline [a] & $-1.16^{* *}$ & 0.26 & $2.11 * *$ & $0.91 * *$ & {$[\mathrm{a}]$} & $0.08 * *$ & -0.05 & -0.04 & $-0.09 * *$ \\
\hline [d] & $-14.54 * *$ & $-14.74 * *$ & $-34.20 * *$ & $-78.16^{* *}$ & [d] & -0.03 & $0.23 * *$ & 0.02 & $0.20 *$ \\
\hline [aa] & $-11.33 * *$ & $-13.97 * *$ & $-28.78 * *$ & $-9.35 * *$ & [aa] & $-0.26^{* *}$ & $0.21 * *$ & -0.02 & 0.15 \\
\hline [ad] & -0.48 & $-2.50 * *$ & $1.14 * *$ & $-2.53 * *$ & [ad] & 0.05 & -0.04 & -0.01 & -0.04 \\
\hline [dd] & $24.55^{* *}$ & $16.51 * *$ & $43.93 * *$ & $5.97 * *$ & [dd] & $0.75^{*}$ & -0.11 & 0.14 & 0.00 \\
\hline Epistasis & Dupl. & Dupl. & Dupl. & Dupl. & Epistasis & Dupl. & Dupl. & Comp. & Comp. \\
\hline \multicolumn{5}{|l|}{$\mathrm{Ch}$} & \multicolumn{5}{|l|}{$\mathrm{FL}$} \\
\hline$[\mathrm{m}]$ & $37.68 * *$ & $38.69 * *$ & $38.25 * *$ & $35.82 * *$ & {$[\mathrm{~m}]$} & $8.06 * *$ & $8.36^{* *}$ & $8.00 * *$ & $7.81 * *$ \\
\hline [a] & 0.72 & $-2.54 * *$ & $-3.25^{* *}$ & $-4.71 * *$ & {$[\mathrm{a}]$} & $2.51 * *$ & $2.57 * *$ & $0.86^{* *}$ & $1.30 * *$ \\
\hline [d] & -0.43 & $12.05 * *$ & $-8.80 * *$ & -0.36 & [d] & $4.21 * *$ & -1.23 & -1.01 & $2.75^{* *}$ \\
\hline [aa] & -2.7 & $11.08 * *$ & $-11.26^{* *}$ & -1.05 & [aa] & -1.43 & 0.13 & $-5.56^{* *}$ & 1.22 \\
\hline [ad] & -0.72 & $-1.44 *$ & $-1.30^{*}$ & -0.03 & [ad] & $-2.23 * *$ & $-1.17^{*}$ & $-2.70 * *$ & $-1.29 * *$ \\
\hline [dd] & $6.63 * *$ & $-18.58 * *$ & $9.04 * *$ & 3.33 & [dd] & $13.69 * *$ & -0.88 & $15.53 * *$ & 0.19 \\
\hline Epistasis & Dupl. & Dupl. & Dupl. & Dupl. & Epistasis & Comp. & Comp. & Dupl. & Comp. \\
\hline \multicolumn{5}{|l|}{ KW } & \multicolumn{5}{|l|}{ GY } \\
\hline$[\mathrm{m}]$ & $4.83^{* *}$ & $5.11^{* *}$ & $4.29 * *$ & $4.39^{* *}$ & {$[\mathrm{~m}]$} & $22.12 * *$ & $23.13 * *$ & $26.62 * *$ & $23.54 * *$ \\
\hline [a] & $0.53 * *$ & $0.51 * *$ & $0.65 * *$ & $0.40^{* *}$ & {$[\mathrm{a}]$} & -0.84 & 2.62 & 1.16 & -0.14 \\
\hline [d] & $0.68 * *$ & -0.31 & $1.02 * *$ & $0.49 *$ & [d] & -4.94 & $13.19 * *$ & 1.52 & 4.96 \\
\hline [aa] & -0.23 & $-0.59 * *$ & $0.76^{* *}$ & $0.43^{*}$ & [aa] & $-6.71^{*}$ & $11.52 * *$ & 0.57 & 3.91 \\
\hline [ad] & $-0.23 *$ & $-0.24 * *$ & $0.41 * *$ & 0.08 & {$[\mathrm{ad}]$} & -1.79 & 1.33 & 1.76 & 0.23 \\
\hline [dd] & $3.32 * *$ & $1.12 * *$ & 0.18 & 0.03 & [dd] & $31.11 * *$ & -10.32 & -9.58 & -4.4 \\
\hline Epistasis & Dupl. & Dupl. & Comp. & Comp. & Epistasis & Dupl. & Dupl. & Dupl. & Dupl. \\
\hline
\end{tabular}

Note. HD: heading date; MD: maturity date; GFP: Grain filling period; GFR: grain filling rate; Ch: Chlorophyll content; FL: flag leaf area; KW: 100-karnels weight (g); GY; grain yield (g/plant). C1: Giza121/RIL1; C2: Giza121/RIL2; Giza126/RIL1; Giza126/RIL2. * and **: significant and highly significant at $95 \%$ and $99 \%$ probability levels, respectively.

\subsection{Inbreeding Depression}

ID\% was less consistent for KW and GY/plant (supplemental Table 2). The lack of uniformity for estimates of inbreeding depression can be related to environmental variation and to its influence on types of generation (Figure 5). The estimated values of potence ratios (PR\%) illustrated that in most $F_{1}$ crosses the estimated PR\% had a positive nature for the characteristics of GFR, FL, KW and GY/plant. These results reflected, generally, various degrees of dominance, i.e., partial- to over-dominance, which is involved in the inheritance of these characteristics. On the contrary, the estimated values of potence ratios in most $F_{1}$ hybrids were negative for HD, $\mathrm{MD}$, and GFP. Negative values of PR\% indicated the presence of various degrees of recessiveness, i.e., partialto under-recessiveness. $\mathrm{PR} \%$ had negative nature for all evaluated $\mathrm{F}_{1}$ hybrids for $\mathrm{HD}$ and ranged from -0.18 to -9.28. These results indicated the presence of partial- to over-dominance, which is involved in the inheritance of 
this characteristic. PR\% refers to complete dominance for C4 in FL and partial dominance for most of the studied crosses. The remaining studied crosses for all characteristic studied showed over dominance towards the higher parent.

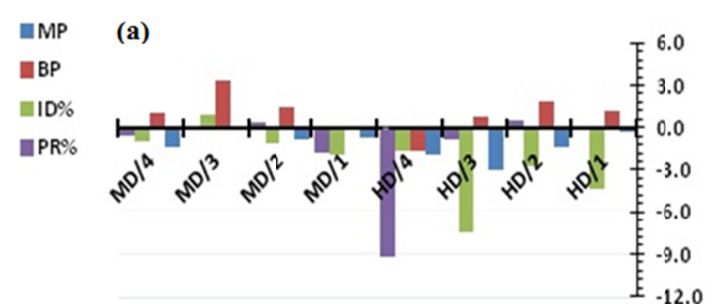

(b)

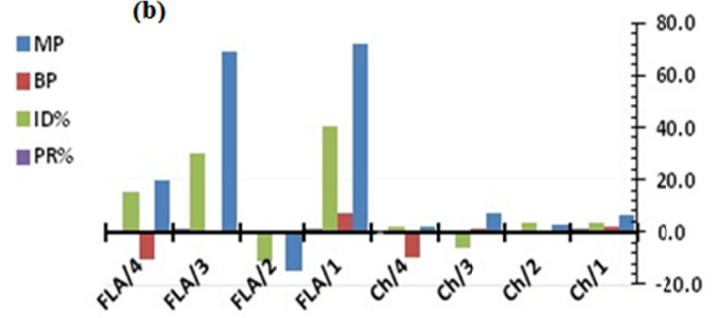

$\square \mathrm{MP}$

$\triangle \mathrm{BP}$ $=10 \%$

(c)

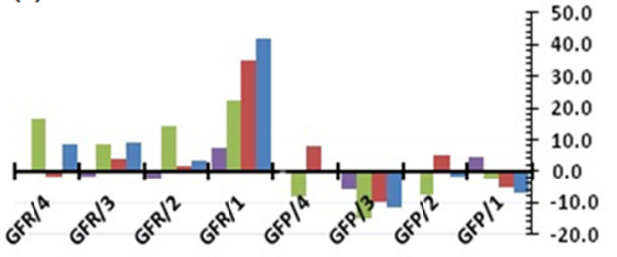

(d)

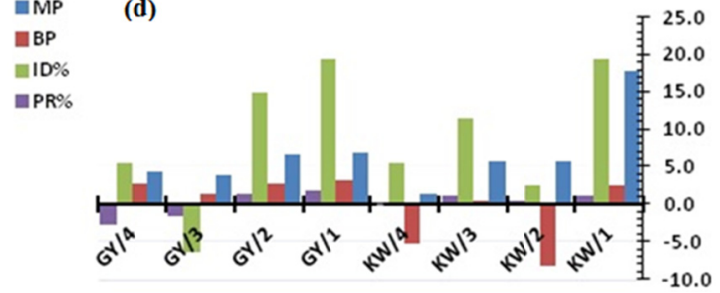

Figure 5. Presence of heterosis, inbreeding depression and potence ratio for the characteristic investigated in all crosses; (a) HD\& MD, (b) Ch\& FLA, (c) GFP\& GFR, and (d) KW\& GY

\subsection{Heritability and Genetic Gains}

Heritability estimates in both broad $\mathrm{h}^{2}$ bs and narrow $\mathrm{h}^{2} \mathrm{~ns}$ senses and expected genetic advance from selection for the studied traits are presented in (Table 5). The $\mathrm{h}^{2}$ bs for HD and MD in all crosses ranged from 76 to $90 \%$, indicating that consistency from one generation to the next for these traits.

Narrow sense $h^{2}$ bn is less likely to be biased upward by dominance and epistatic effects. Values obtained for KW and GY were more consistent among the broad sense than the narrow sense estimates. Very low narrow sense estimates were obtained for Giza126/RIL2, the broad sense heritability for GY and the earliness characteristic in all crosses were considerably larger than the corresponding narrow sense estimates. In view of the rather low narrow sense heritability estimates, the expected response to a selection from these populations generally low.

\subsection{The Predicted Genetic Advance}

The predicted genetic advance estimates were low to moderate for all studied traits and ranged ranging from $2.05 \%$ for MD in $\mathrm{C} 4$ to $51.17 \%$ for FL in $\mathrm{C} 2$ (Table 5). These results indicated the possibility of practicing selection in early generations and obtaining high yielding genotypes.

Table 5. The broad, narrow senses heritability and genetic advance from selection for eight studied traits

\begin{tabular}{|c|c|c|c|c|c|c|c|c|c|}
\hline \multirow{2}{*}{ Crosses } & \multicolumn{2}{|l|}{$\mathrm{Hb}$} & \multicolumn{2}{|l|}{ GA } & & \multicolumn{2}{|l|}{$\mathrm{Hb}$} & \multicolumn{2}{|l|}{ GA } \\
\hline & $\mathrm{h}^{2}(\mathrm{bs})$ & $\mathrm{h}^{2}(\mathrm{~ns})$ & $\Delta \mathrm{g}$ & $\Delta \mathrm{g} \%$ & & $\mathrm{~h}^{2}(\mathrm{bs})$ & $\mathrm{h}^{2}(\mathrm{~ns})$ & $\Delta \mathrm{g}$ & $\Delta \mathrm{g} \%$ \\
\hline$\underline{\mathrm{HD}}$ & & & & & MD & & & & \\
\hline $\mathrm{C} 1$ & 83.18 & 52.76 & 4.72 & 5.09 & $\mathrm{C} 1$ & 82.45 & 33.25 & 2.99 & 2.17 \\
\hline $\mathrm{C} 2$ & 90.01 & 66.56 & 6.95 & 7.3 & $\mathrm{C} 2$ & 85.13 & 43.45 & 4.10 & 2.94 \\
\hline $\mathrm{C} 3$ & 76.27 & 40.90 & 3.05 & 3.12 & C3 & 85.79 & 40.91 & 3.53 & 2.54 \\
\hline $\mathrm{C} 4$ & 86.05 & 64.79 & 6.51 & 6.6 & $\mathrm{C} 4$ & 87.75 & 31.64 & 2.88 & 2.05 \\
\hline GFP & & & & & GFR & & & & \\
\hline $\mathrm{C} 1$ & 41.61 & 13.30 & 0.39 & 0.87 & $\mathrm{C} 1$ & 85.56 & 48.13 & 0.2 & 32.89 \\
\hline $\mathrm{C} 2$ & 58.34 & 47.74 & 1.69 & 3.72 & $\mathrm{C} 2$ & 88.61 & 42.05 & 0.2 & 37.49 \\
\hline $\mathrm{C} 3$ & 82.69 & 56.99 & 1.92 & 4.07 & $\mathrm{C} 3$ & 91.11 & 21.41 & 0.1 & 18.97 \\
\hline $\mathrm{C} 4$ & 56.65 & 44.00 & 1.58 & 3.48 & $\mathrm{C} 4$ & 87.81 & 32.54 & 0.15 & 29.98 \\
\hline
\end{tabular}


Table 5. Continued

\begin{tabular}{|c|c|c|c|c|c|c|c|c|c|}
\hline \multirow{2}{*}{ Crosses } & \multicolumn{2}{|l|}{$\mathrm{Hb}$} & \multicolumn{2}{|l|}{ GA } & & \multicolumn{2}{|l|}{$\mathrm{Hb}$} & \multicolumn{2}{|l|}{ GA } \\
\hline & $\mathrm{h}^{2}(\mathrm{bs})$ & $\mathrm{h}^{2}(\mathrm{~ns})$ & $\Delta \mathrm{g}$ & $\Delta \mathrm{g} \%$ & & $\mathrm{~h}^{2}(\mathrm{bs})$ & $\mathrm{h}^{2}(\mathrm{~ns})$ & $\Delta \mathrm{g}$ & $\Delta \mathrm{g} \%$ \\
\hline$\underline{F L}$ & & & & & $\underline{\mathrm{Ch}}$ & & & & \\
\hline $\mathrm{C} 1$ & 80.71 & 54.00 & 3.43 & 42.53 & $\mathrm{C} 1$ & 88.04 & 39.14 & 3.11 & 8.27 \\
\hline $\mathrm{C} 2$ & 87.80 & 62.94 & 4.28 & 51.17 & $\mathrm{C} 2$ & 91.56 & 38.52 & 3.31 & 8.56 \\
\hline $\mathrm{C} 3$ & 63.55 & 44.73 & 2.08 & 26.06 & $\mathrm{C} 3$ & 91.01 & 43.38 & 3.97 & 10.37 \\
\hline $\mathrm{C} 4$ & 80.76 & 61.39 & 3.59 & 46.05 & $\mathrm{C} 4$ & 90.64 & 24.25 & 2.21 & 6.18 \\
\hline KW & & & & & GY & & & & \\
\hline $\mathrm{C} 1$ & 75.56 & 30.97 & 0.36 & 7.43 & $\mathrm{C} 1$ & 84.99 & 33.34 & 5.88 & 26.57 \\
\hline $\mathrm{C} 2$ & 69.28 & 33.11 & 0.35 & 6.81 & $\mathrm{C} 2$ & 88.45 & 21.08 & 4.12 & 17.81 \\
\hline $\mathrm{C} 3$ & 63.44 & 40.78 & 0.4 & 9.33 & $\mathrm{C} 3$ & 88.2 & 19.15 & 3.60 & 13.52 \\
\hline $\mathrm{C} 4$ & 71.98 & 29.00 & 0.31 & 7.15 & $\mathrm{C} 4$ & 88.23 & 14.52 & 2.67 & 11.33 \\
\hline
\end{tabular}

Note. Hb: Heritability percentage; GA: genetic advance. HD: heading date; MD: maturity date; GFP: Grain filling period; GFR: grain filling rate; Ch: Chlorophyll content; FL: flag leaf area; KW: 100-karnels weight (g); GY; grain yield (g/plant). C1: Giza121/RIL1; C2: Giza121/RIL2; Giza126/RIL1; Giza126/RIL2.

\section{Discussion}

Selection of the appropriate parents to be used in artificial crosses is one of the main decisions faced by plant breeders that will facilitate the exploitation of maximum genetic variability and production of superior recombinant genotypes, so selecting the parents based on the molecular variation can take into account with high phenotypic variation in the traits under study. One-dimensional SDS-PAGE electrophoresis analysis (Laemmli, 1970) separations are shown in (Figure 2), the analysis shows that the most variance between the parents was in prolamin fractions (hordeins), and that mean the parents which used in this study were abroad-relative.

The yield performance results for the six- populations suggest that late heading is dominant to early heading, Moreover, the 100-KW and GY of $\mathrm{F}_{2}$ and backcross populations were considerably higher than the best parent, which indicates a high heterotic effect (Abd El-Aty et al., 2011). The morphological and phenological evaluation of barley is necessary to determine their importance on grain yield increase. Therefore, grain number per spike and grain weight is the other important yield components that affect grain yield (Yadav et al., 2015). The current results explained the four crosses' traits were quantitatively inherited and could be controlled by multiple genes (Zhang et al., 2015).

\subsection{Phenotypic Correlation Coefficients}

The relationship between yield and heading date was not consistent from the cross to another and the $r$ values were quite low, indicated the importance of these traits in yield improvement and would be considered in selection program (Table 3). In barley, the importance of flag leaf in determining grain yield was also intensively studied (Xue et al., 2008). Teng et al. (2004) reported that leaf chlorophyll content was positively correlated with photosynthetic capacity and high chlorophyll content as a favorable trait in rice production. Besides grain yield, which represents the ultimate selection objective, a number of yields-related traits have received much attention, such as chlorophyll content, flag leaf area, days to heading, plant height, 1000-kernel weight and grains per spike in spring barley by Teng et al. (2004) and Abd El-Aty et al. (2011).

\subsection{Types of Gene Action}

The major contribution by dominance [d] effects to variation in $\mathrm{C} 2, \mathrm{C} 3$, and $\mathrm{C} 4$ crosses in all traits except for GFR and FL, which were indicated by the relative magnitude of the parameter [d] to the parameter [m]. A significance of [a] and [d] components indicated that both additive and dominance gene effects were important in the inheritance of these traits and selecting desirable traits would be effective in the late generations (Gamble, 1962; Abd El-Aty et al., 2011). Highly positive significant for additive $\times$ additive [aa] effects were detected for; $\mathrm{KW}$ in $\mathrm{C} 3$ and $\mathrm{C} 4$; $\mathrm{GY}$ in $\mathrm{C} 2$, while negative significant effects for [aa] type was found for $\mathrm{HD}$ in $\mathrm{C} 1$ and $\mathrm{C} 3$, $\mathrm{MD}$ in $\mathrm{C} 2, \mathrm{FL}$ in $\mathrm{C} 3, \mathrm{Ch}$ in $\mathrm{C} 3$ and $\mathrm{KW}$ in $\mathrm{C} 2$. Mulbah et al. (2015) have found that additive gene effects make a greater contribution to the total genetic variation than the estimates obtained in his study on rice. The absolute relative magnitudes of the epistatic gene effects to the mean effects are somewhat variable depending on the cross. In some crosses, notably, Giza121/RIL2 and Giza126/RIL1 in most traits, the absolute magnitude of the epistatic gene effects are larger than the mean effects and come up to that of the dominance effects. 
Duplicate epistasis was observed, as revealed by differences in signs of [d] and [dd] in crosses, which exhibited significant epistasis, while similar signs of [d] and [dd] in complementary epistasis. Complementary epistasis was prevailing in $\mathrm{C} 3$ and $\mathrm{C} 1$ crosses for $\mathrm{HD}$ and $\mathrm{MD}$, respectively. the $\mathrm{C} 1$, the $\mathrm{C} 2$, and $\mathrm{C} 4$ crosses in $\mathrm{LA}$, the $\mathrm{C} 3$ and $\mathrm{C} 4$ crosses for KW, which coincide with the results obtained by Sharma et al. (2003). These findings illustrated that duplicate epistasis was prevailing for most traits (Yadav et al., 2015). Chaudhary et al. (1974) detected that the epistatic duplicate type was predominant over the complementary type.

\subsection{Heterosis}

Yield in barley, like in other crops, is a very complex trait and is a result of the interaction between various yield components and the environment. Knowledge of the association between yield-related traits is of immense importance to the selection of desired combinations of characteristics Zhang et al., (2015). Heterosis led to a considerable increase in total biological yield, grain yield and straw yield (Finlay \& Wilkinson, 1963; Amer et al., 2012a). The relative effect of Heterosis clearly depended on the genetic background, crosses between genetically divergent or non-adapted materials led to a higher relative effect of Heterosis than crosses among related or adapted materials (Abd El-Aty et al., 2011). Yield, as well as yield components, is determined by several genes, with specific interactions that make breeding for yield increase more difficult. Different degrees of gene effects, i.e., partial to over-dominance, were clear to be involved in the inheritance of FL, KW and GY/plant (Abd El-Aty et al., 2011; Elakhdar et al., 2016a).

Heritability values indicate the degree of genetic relationship between the performance of parents and progeny which is an important aspect for obtaining genetic progress on artificial selection. The broad sense heritability for GY and the earliness characteristic in all crosses were considerably larger than the corresponding narrow sense estimates (Addisu \& Shumet, 2015). Very low narrow sense estimates were obtained for Giza126/RIL2, which means the expected response to selection from these populations generally low. Esparza Martínez and Foster (1998) reported that grain weight is a relatively stable yield component in barley. Hence, selection for traits phenological shows the higher variation in all conditions is more effective and having appropriate heritability.The predicted genetic advance estimates were low to moderate for all studied traits and ranged ranging from $2.05 \%$ for $\mathrm{MD}$ in $\mathrm{C} 4$ to $51.17 \%$ for $\mathrm{FL}$ in $\mathrm{C} 2$. These results indicated the possibility of practicing selection in early generations and obtaining high yielding genotypes (Abd El-Aty et al., 2011). Therefore, the selection in the present those particular populations should be effective and satisfactory for successful breeding purposes. The dominance effects $\left(\sigma^{2} \mathrm{D}\right)$ were greater than those of additive effects $\left(\sigma^{2} \mathrm{~A}\right)$ for most studied traits (Supplemental Table 3), indicating that the selection for these traits might be non-effective in early generations to improve such traits in the four studied crosses (Addisu \& Shumet, 2015). The estimate of genetic advance $(\Delta \mathrm{g} \%)$, which evaluates the expected rate of genetic gain under directional selection, was inconsistent among crosses and in some cases it was zero due to the lack of additive variance.

It can be concluded that the degree of improving the studied traits was successfully based on the high heritability values and positive additive genetic advance shown by the different traits, especially; KW and GY as was reported by Aidun et al. (1990) and Yadav et al. (2015). Generally, the most biometrical parameters resulted from the first and the third cross (Giza121/RIL1 and Giza126/RIL2) were found to be higher in magnitude in comparison with those from other crosses. Consequently, it could be concluded that the above-mentioned crosses would be of interest in breeding programs for improving traits for earliness, yield, and its components.

\section{Conclusion}

Because of the need for harvesting and threshing of individual plants, the grain yield is difficult to quantify. Therefore, indirect selection strategies for less complex traits, with higher heritability and good correlation with grain yield, may facilitate the selection in generations with high levels of heterosis. The chlorophyll content and flag leaf are one of the greatest components in determining grain yield potential in barley. So that, effective selection in plant breeding is based on information about the extent to which observed differences in the traits under selection are highly heritable and the extent to which they are correlated with each other and also with GY.

\section{References}

Abd El-Aty, M., Amer, Kh., Eldegwy, I., \& ElAkhdar, A. (2011). Genetic studies on yield and its components in some Barley Crosses. Journal of Plant Production, 11, 1537-1550.

Addisu, F., \& Shumet, T. (2015). Variability, Heritability and Genetic Advance for Some Yield and Yield Related Traits in Barley (Hordeum vulgare L.) Landraces in Ethiopia. International Journal Plant Breeding and Genetic, 2, 68-76. https://doi.org/10.3923/ijpbg.2015.68.76 
Aidun, A., Harvey, B., \& Rossnagel, B. (1990). Heritability and genetic advance of hull peeling in two-row barley. Canadian Journal of Plant Science, 70, 481-485. https://doi.org/10.4141/cjps90-056

Allard, R. W., \& Jain, S. K. (1962). Population Studies in Predominantly Self-Pollinated Species. II. Analysis of Quantitative Genetic Changes in a Bulk-Hybrid Population of Barley. Evaluation, 16, 90-101. https://doi.org/10.2307/2406269

Amer, Kh., Eid, A., Elakhdar, A., \& El-Shawy, E. (2012a). Combining ability and heterosis in five barley genotypes for some economic traits. Egyptian Journal of Agricultural Research, 90, 105-116.

Amer, Kh., Eid, A., El-Sayed, M., \& Elakhdar, A. (2012b). Estimation of some genetic parameters for yield and its components in some barley genotypes. Egyptian Journal of Agricultural Research, 90, 117-130.

Chaudhary, B., Singh, R., \& Kakar, S. (1974). Estimation of genetic parameters in barley (Hordeum vulgare L.). Theoretical and Applied Genetics, 45, 192-196. https://doi.org/10.1007/BF00264998

Elakhdar, A., Abd El-sattar, M., Amer, K., Assma, R., \& Kumamaru, T. (2016b). Population structure and marker-trait association of salt tolerance in barley (Hordeum vulgare L.). Comptes rendus Biologies, 339, 454-461. https://doi.org/10.1016/j.crvi.2016.06.006

Elakhdar, A., Abd El-sattar, M., Amer, Kh., \& Kumamaru, T. (2016a) Genetic diversity and association analysis among Egyptian barley (Hordeum vulgare L.) genotypes with different adaptations to saline conditions analyzed by SSR markers. Australian Journal of Crop Science, 10, 637-645. https://doi.org/10.21475/ ajcs.2016.10.05.p7331

Esparza, Martínez, J. H., \& Foster, A. E. (1998). Genetic analysis of heading date and other agronomic characters in barley (Hordeum vulgare L.). Euphytica, 99, 145-153. https://doi.org/10.1023/A:10183806 17288

Falconer, D. S., \& Mackay, F. C. (1996). Introduction to Quantitative Genetics (p. 464). Longman, New York.

Finlay, K., \& Wilkinson, G. (1963). The analysis of adaptation in a plant-breeding programme. Australian Journal of Research, 14, 742. https://doi.org/10.1071/AR9630742

Gamble, E. E. (1962). Gene effects in corn (Zea Mays L.): i. Separation and relative importance of gene effects for yield. Canadian Journal of Plant Science, 42, 339-348. https://doi.org/10.4141/cjps62-048

Harlan, J. (1976). Barley. In N. W. Simmonds (Ed.), Evolution of crop plants (pp. 93-98). Longman, London.

Hayman, B., \& Mather, K. (1955). The description of genie interaction in continuous variation. Biometrics, 1(1), 69-82. Retrieved from http://www.jstor.org/stable/3001481

Johnson, H. W., Robinson, H. F., \& Comstock, R. E. (1955). Estimates of Genetic and Environmental Variability in Soybeans. Agronomy Journal, 47, 314-318. https://oi.org/10.2134/agronj1955.00021962004700 070009x

Laemmli, U. K. (1970). Cleavage of Structural Proteins during the Assembly of the Head of Bacteriophage T4. Nature, 227, 680-685. https://doi.org/10.1038/227680a0

Miller, P. A., Williams, J. C., Robinson, H. F., \& Cemstock, R. F. (1958). Estimates of genotypic and environmental variances in upland cotton and their implication in selection. Agronomy Journal, 50, $126-131$. https://doi.org/10.2134/agronj1958.00021962005000030004x

Sharma, S., Sain, R., \& Sharma, R. (2003). The genetic control of flag leaf length in normal and late sown durum wheat. Journal of Agricultural Science, 141, 323-331. https://doi.org/10.1017/S0021859603003642

Smith, H. (1952). Fixing Transgressive Vigor in Nicotiana Rustica (p. 552). Iowa State College Press, Ames, USA.

Teng, S., Qian, Q., Zeng, D., Kunihiro, Y., Fujimoto, K., Huang, D., \& Zhu, L. (2004). QTL analysis of leaf photosynthetic rate and related physiological traits in rice (Oryza sativa L.). Euphytica, 135, 1-7. https://doi.org/10.1023/B:EUPH.0000009487.89270.e9

Xue, D., Chen, M., Zhou, M., Chen, S., Mao, Y., \& Zhang, G. (2008). QTL analysis of flag leaf in barley (Hordeum vulgare L.) for morphological traits and chlorophyll content. Journal of Zhejiang University of Science, 12, 938-43. https://doi.org/10.1631/jzus.B0820105

Yadav, S. K., Singh, A. K., Pandey, P., \& Singh, S. (2015). Genetic Variability and Direct Selection Criterion for Seed Yield in Segregating Generations of Barley (Hordeum vulgare L.). American Journal of Plant Sciences, 9, 1543-1549. https://doi.org/10.4236/ajps.2015.69153 
Zhang, X., Lu, C., Xu, R., \& Zhou, M. (2015). Development of molecular markers linked to barley heterosis. Euphytica, 203, 309-319. https://doi.org/10.1007/s10681-014-1265-3

\section{Copyrights}

Copyright for this article is retained by the author(s), with first publication rights granted to the journal.

This is an open-access article distributed under the terms and conditions of the Creative Commons Attribution license (http://creativecommons.org/licenses/by/4.0/). 